\title{
Adolescent Weight Status and Related Behavioural Factors: Web Survey of Physical Activity and Nutrition
}

\author{
Kate E. Storey, ${ }^{1}$ Laura E. Forbes, ${ }^{2}$ Shawn N. Fraser, ${ }^{3}$ John C. Spence, ${ }^{4}$ \\ Ronald C. Plotnikoff, ${ }^{5}$ Kim D. Raine, ${ }^{6}$ and Linda J. McCargar ${ }^{2}$ \\ ${ }^{1}$ Department of Public Health Sciences, School of Public Health, University of Alberta, 6-50 University Terrace, 8303-112 Street, \\ Edmonton, AB, Canada T6G 2T4 \\ ${ }^{2}$ Alberta Institute for Human Nutrition, Department of Agricultural, Food and Nutritional Science, University of Alberta, \\ 4-126 Li Ka Shing Centre for Health Research Innovation, Edmonton, AB, Canada T6G 2E1 \\ ${ }^{3}$ Centre for Nursing and Health Studies, Athabasca University, 1 University Drive, Athabasca, AB, Canada T9S $3 A 3$ \\ ${ }^{4}$ Faculty of Physical Education and Recreation, University of Alberta, E-488 Van Vliet Centre, Edmonton, AB, Canada T6G $2 \mathrm{H} 9$ \\ ${ }^{5}$ School of Education, The University of Newcastle, HPE 3.08, Health and Physical Education Building, University Drive, \\ Callaghan, NSW 2308, Australia \\ ${ }^{6}$ Centre for Health Promotion Studies, School of Public Health, University of Alberta, 1001 College Plaza, 8215-112 Street, \\ Edmonton, AB, Canada T6G 2E1
}

Correspondence should be addressed to Kate E. Storey, kate.storey@ualberta.ca

Received 9 June 2011; Revised 23 September 2011; Accepted 8 October 2011

Academic Editor: Douglas Thompson

Copyright (C) 2012 Kate E. Storey et al. This is an open access article distributed under the Creative Commons Attribution License, which permits unrestricted use, distribution, and reproduction in any medium, provided the original work is properly cited.

\begin{abstract}
Purpose. To identify whether non-overweight students were different from their overweight or obese peers with respect to diet, suboptimal meal behaviours, and physical activity using a self-administered web-based survey. Methods. 4097 adolescents living in Alberta, Canada completed Web-SPAN (Web Survey of Physical Activity and Nutrition). Students were classified as overweight or obese, and differences were described in terms of nutrient intakes, physical activity, and meal behaviours. Results. Non-overweight students consumed significantly more carbohydrate and fibre, and significantly less fat and high calorie beverages, and had a higher frequency of consuming breakfast and snacks compared to overweight or obese students. Both non-overweight and overweight students were significantly more active than obese students. Conclusions. This research supports the need to target suboptimal behaviours such as high calorie beverage consumption, fat intake, breakfast skipping, and physical inactivity. School nutrition policies and mandatory physical education for all students may help to improve weight status in adolescents.
\end{abstract}

\section{Introduction}

Obesity has been recognized as a significant public health challenge worldwide. The obesity epidemic is of concern in Canadian adolescents due to the dramatic increase in prevalence over the past 25 years [1]. Further, numerous health consequences of adolescent obesity exist including risk for cardiovascular disease, type 2 diabetes [2], and persistence of obesity into adulthood $[3,4]$. Equally concerning are psychosocial consequences such as discrimination and teasing that may occur, which can have a long-term effect on self-esteem and body image [5]. Obesity presents an enormous burden to our health care system, estimated in the billions of dollars, which is only expected to increase with the dramatic rise in obesity prevalence [6].

Given the numerous consequences of obesity, surveillance systems and measurement tools are needed to determine the effectiveness of obesity prevention programs and interventions [7]. However, it is becoming increasingly difficult to collect relevant and geographically diverse information in a time- and cost-effective manner. Web-based methods of surveillance provide a cost-effective means to survey large numbers of participants concurrently throughout wide geographic areas. Access to hard-to-reach areas is enhanced, thus improving the ability to obtain a representative sample [8]. The Web Survey of Physical Activity and Nutrition 
(Web-SPAN), a self-administered web-based survey for adolescents, has previously been validated [9]. However, WebSPAN has not yet been used to determine the relationship between bodyweight status and health behaviours such as dietary intake and suboptimal meal behaviours. Therefore, this study provides the much-needed insight on how webbased methods of surveillance can be used to further our understanding of the factors that contribute to overweight/obesity in youth and will help inform intervention development and refinement.

Although several studies have examined the relationship between overweight/obesity and obesity determinants, few have utilized a web-based platform in order to capture this information. Previous studies have indicated that obesity is a complex condition involving individual/behavioural, environmental, and social factors. Further, it has been proposed that a basic imbalance of energy intake and energy expenditure leads to increased adiposity [10]. Specifically, individual behaviours such as increased consumption of high calorie foods (which include high calorie beverages) [1, 11-13], physical inactivity, and increased sedentary activity [14-16] have been identified as key factors contributing to the development of obesity.

Therefore, the purpose of this study was to use a webbased method of surveillance to investigate the current bodyweight status of Alberta adolescents and to identify whether non-overweight students were different from their overweight or obese peers with respect to macronutrient intakes, consumption of Other Foods (foods not included in Canada's Food Guide), suboptimal meal behaviours including breakfast skipping and consuming meals away from home, and physical activity levels. It was hypothesized that non-overweight students would have different intakes including lower intakes of fat and Other Foods, and a lower frequency of meal skipping and consuming meals away from home. Further, it was hypothesized that non-overweight students would be more active than their overweight and obese peers.

\section{Methods}

2.1. Participants. The Web Survey of Physical Activity and Nutrition (Web-SPAN) was a self-administered web-based survey of grade 7 to 10 students that assessed diet, physical activity, related meal behaviours (i.e., meal skipping and consuming meals away from home), and height and weight and is described below. All 59 public and separate school boards in the province of Alberta, Canada were selected for participation, which included schools in both rural and urban areas, public schools, Catholic schools, and private schools. Of these 59 school boards, 48 (81\%) agreed to participate and an average of seven schools within each school board was randomly chosen and contacted after obtaining school board approval. Private schools (approximately 10\% of all Alberta schools) were also included in the study and were selected to ensure that they were appropriately represented in the sample. These schools were initially stratified according to the five Alberta Education zones in the province (Calgary and South, Central, Edmonton and area, North Central, North) and were then randomly selected.

In total, 18,484 students were sent consent forms across 363 schools and 4981 adolescents agreed to participate in the study. However, participating students who signed on to the website but did not complete the survey $(n=9)$, and students with extreme values of BMI, total caloric intake, or physical activity levels based on outlier analyses (nonmutually exclusive outliers: BMI, $n=35$; total caloric intake, $n=24$; physical activity, $n=14$; total outliers removed, $n=71$ ) were excluded. BMI classification could not be determined on 804 students due to missing height and/or weight, thus they were excluded from the analyses. The final sample was 4097 students (boys $=1974$; girls $=2123$; mean age $=13.7$ years) from 136 schools (37\% school response rate) within 44 school boards ( $75 \%$ board response rate). Age and sex characteristics of our overall sample reflected the sampling frame of the provincial school population for grades 7-10: the mean age of our sample was $13.7( \pm 1.2)$ years versus $13.3( \pm 1.3)$ years for grade $7-10$ Alberta school youth $(n \sim 130,000)$, and the proportion of males in our sample was $48 \%$ versus $51 \%$ for the province. During data collection, students were free to end the survey at any time and were not required to answer every question in order to participate. Therefore, sample size varied throughout the analyses.

\subsection{Measures}

2.2.1. Web-SPAN. Web-SPAN was a self-administered webbased survey that was developed at the University of Waterloo and modified by researchers at the University of Alberta in order to include questions regarding meal behaviours (i.e., meal skipping and consuming meals away from home), selfefficacy, and physical activity. Students respond to electronic survey questions providing information on height, weight, dietary intake, physical activity, and other health behaviours. Web-SPAN has previously been validated [9] and has been described elsewhere [17-21].

2.2.2. Weight Status. Students provided self-reported height and weight. Body mass index (BMI) was calculated (weight [kilograms]/height $\left[\right.$ meters $\left.^{2}\right]$ ), and students were categorized as overweight or obese using the International Obesity Task Force (IOTF) cut-offs [22]. Derived from adult BMI cut-off points ( 25 and $30 \mathrm{~kg} / \mathrm{m}^{2}$ for overweight and obesity, resp.), age and sex specific cut-off points for youth 2 to 18 years of age were extrapolated by placing these values $\left(25 \mathrm{~kg} / \mathrm{m}^{2}\right.$ and $\left.30 \mathrm{~kg} / \mathrm{m}^{2}\right)$ at 18 years of age where prevalence of overweight and obesity were matched. The IOTF cut-offs were used to determine overweight and obesity status based on the recommendation of Dietitians of Canada, the Canadian Paediatric Society, the College of Family Physicians of Canada, and the Community Health Nurses Association of Canada [23]. Among a subsample of 459 students in our study, Web-SPAN showed good agreement for self-reported height $(r=0.88)$ and weight $(r=0.94)$ when compared to measured height and weight [9]. 
2.2.3. Dietary Intake. As part of Web-SPAN, a 24-hour webbased dietary recall was administered to students to measure dietary intake using the Food Behaviour Questionnaire developed at the University of Waterloo [24] and modified by researchers at the University of Alberta [17]. Responding to the electronic survey questions, students reported all foods and beverages consumed during the previous day. To help students recall their intake, portion size images and cues regarding beverage intake were provided. The 24-hour recall component of the Food Behaviour Questionnaire (FBQ) has been validated using several methods and has been described previously [9]. Briefly, in comparison to a dietitianadministered 24-hour dietary recall, the FBQ showed good agreement for total energy and nutrient intakes [25], and compared to a 3-day food record, intraclass correlation coefficient values were within ranges reported elsewhere in the adolescent population [9].

A measure of diet quality was used to classify students into groups of poor (meeting minimum servings of 0-1 food group), average (2-3 food groups), or superior (all 4 food groups) diet quality using a food-based diet quality index [26] modified to reflect Canada's Food Guide to Healthy Eating (CFGHE) [27] foods [17]. The number of servings from each CFGHE food group [27] was calculated using data from the 24-hour dietary recall and included the following food groups: Grain Products, Vegetables and Fruit, Milk Products, and Meat and Alternatives. Foods that were not classified as CFGHE foods were categorized as Other Foods and further divided into the following subcategories: foods containing mostly sugar (e.g., candies), high salt/fat foods (e.g., potato chips), high calorie beverages (e.g., regular soft drinks), low calorie beverages (e.g., low calorie soft drinks), or high sugar/fat foods (e.g., pastries) based on Canadian Nutrient File definitions [28]. The CFGHE was subsequently revised and the new food guide [29] was released in early 2007. In spite of this, the 1992 CFGHE was the government recommendation during data collection and was also a component of Alberta school curriculum [30, 31]. Therefore, it was most appropriate to compare intakes to the 1992 CFGHE recommendations. Macronutrient intakes were assessed using ESHA Food Processor (version 7.9; Salem, OR) and the 2001b Canadian Nutrient File [28] database.

2.2.4. Suboptimal Meal Behaviours. Survey questions examining meal behaviours (i.e., meal skipping and consuming meals away from home) were comparable to questions developed for Project EAT (Eating Among Teens), a wellestablished survey instrument $[32,33]$. Frequency of meal consumption was assessed by asking "How often do you usually eat?" followed by "breakfast," "lunch," "dinner," "morning snacks," "afternoon snacks," or "evening snacks" with response options of "Never," "On weekends only," "Less than half of the week ( $\leq 3$ days/week)," "More than half of the week ( $\geq 4$ days/week)," "Every day," and "Not answered." Frequency of consuming meals away from home was assessed by asking "How often do you eat meals or snacks prepared away from home?" with response options of "rarely or never," "once a month," "once a week," "2-6 times a week," and "once a day." The following locations were assessed: school cafeteria, fast food restaurant or take out, other restaurants, vending machines, snack bars, and convenience stores.

2.2.5. Physical Activity. A web-based version of the Physical Activity Questionnaire for Older Children (PAQ-C) was used to assess physical activity levels over the previous 7-day period. The PAQ-C was specifically designed for Canadian school-aged youth and includes components on physical activity during the school day as well as after school and weekend activity [34]. The questionnaire consists of 9 items which are used to calculate an activity score (scores range from 1.00 to 5.00). The PAQ-C has been shown to be a reliable [35] and valid [36] method to assess physical activity in youth. In addition, among a subsample of 411 students in our study, when compared to the paper-based PAQ-C, the web-based PAQ-C showed good agreement $(r=0.70)$ [9].

2.3. Procedures. School boards and schools were individually contacted by mail and followup phone calls were made to request permission to survey students. Parents and students received information letters, and parental consent was obtained using active consent. All students provided assent after signing on to the web-based survey. The anonymous 24-page survey took approximately 45 minutes to complete and was conducted during class time within the school day. Survey data were collected between January and November 2005 (except in July and August when schools were closed for summer). This research was approved by a university ethics board and by all participating school boards and schools.

2.4. Statistical Analyses. Overweight and obesity prevalence were analyzed using descriptive statistics. Four $2 \times 3$ multivariate analyses of covariance (MANCOVA) were used to evaluate the association between gender and BMI classification for the four sets of dependent variables: nutrient intakes, Other Foods categories, frequency of meal consumption, and location of meal consumption. Total caloric intake was used as the covariate for all four MANCOVAs. Univariate followups were completed on significant MANCOVA results for dependent variables. Prior to the MANCOVA analyses, the assumption of homogenous slopes [37, 38] was tested, and interactions indicated that the slopes differed among levels of the independent variables. Therefore, adjusted values were based on custom models which included these interactions for the following MANCOVA analyses: macronutrients, Other Foods, and frequency of meal consumption. Differences in physical activity levels and diet quality scores between non-overweight, overweight, and obese students were assessed using a $2 \times 3$ analysis of variance (ANOVA) for gender and weight status.

Statistical analyses were performed using the software program SPSS (version 15.0; SPSS Inc, Chicago, Ill). A criterion $\alpha$-level of $P<0.05$ was used for all statistical comparisons given the small effect sizes previously observed using Web-SPAN [17-20]. 
TABle 1: Percentage of overweight and obesity, by gender, among adolescents aged 11 to 17 years*.

\begin{tabular}{lccc}
\hline BMI Classification $^{\dagger}$ & $\begin{array}{c}\text { Total } \\
(n=4097)\end{array}$ & $\begin{array}{c}\text { Boys } \\
(n=1974)\end{array}$ & $\begin{array}{c}\text { Girls } \\
(n=2123)\end{array}$ \\
\hline Overweight & $15.1^{\ddagger}$ & 19.0 & 11.4 \\
Obese & 6.0 & 7.5 & 4.6 \\
\hline
\end{tabular}

${ }^{*}$ Four students were younger than age 11 due to mixed grade level classrooms.

${ }^{\dagger}$ Classified according to the International Obesity Task Force cut-offs [22].

${ }^{\ddagger}$ Prevalence expressed as a percentage.

\section{Results}

3.1. Weight Status. Observed percentage of overweight and obesity, by gender, are presented in Table 1. In total, $21.1 \%$ of students $(26.5 \%$ boys; $16.0 \%$ girls) were considered overweight or obese.

3.2. BMI Classification and Nutrient Intakes. Multivariate $F$ values for BMI classification (Wilks' Lambda $=1.00$, $\left.F[8,8134]=3.46, P=0.039, \eta_{p}^{2}=0.002\right)$ were significant, while the interaction between BMI classification and gender was not significant (Wilks' Lambda $=1.00, F[8,8134]=$ $\left.0.59, P=0.788, \eta_{p}^{2}=0.001\right)$ for nutrient intakes. Univariate followup analyses for BMI classification indicated that non-overweight students consumed significantly more carbohydrate and fibre, and significantly less fat compared to both overweight and obese students. Significant differences did not exist between overweight and obese students, or for protein intakes between BMI classifications (Table 2).

No significance was observed for the main effect of BMI classification (Wilks' Lambda $=1.00, F[10,8132]=0.88$, $\left.P=0.552, \eta_{p}^{2}=0.001\right)$ or the interaction between BMI classification and gender (Wilks' Lambda $=1.00, F[10,8132]=$ 1.03, $\left.P=0.417, \eta_{p}^{2}=0.001\right)$ with Other Foods subcategories (MANCOVA). The results of comparisons between intakes from the Other Foods subcategories and BMI classification are presented in Table 2. Although significant differences were not observed based on the MANCOVA, significance was observed for high calorie beverages based on univariate analyses where non-overweight students consumed significantly less high calorie beverages compared to obese students. No significant differences were observed between BMI classification and diet quality $\left(\chi^{2}[4]=5.31\right.$, $P=0.257)$.

3.3. BMI Classification and Suboptimal Meal Behaviours. Significant main effects for BMI classification (Wilks' Lambda $\left.=0.99, F[8,6202]=2.88, P=0.003, \eta_{p}^{2}=0.004\right)$, but not for the interaction between BMI classification and gender (Wilks' Lambda $=1.00, F[8,6202]=0.77, P=0.627, \eta_{p}^{2}=$ $0.001)$ were observed when meal frequency was assessed using MANCOVA. Followup univariate analyses revealed that non-overweight students had a higher frequency of consuming breakfast and snacks compared to obese students. Non-overweight students also consumed snacks more frequently than overweight students. No differences were observed for lunch or dinner consumption (Table 3).
The association between BMI classification and gender with frequency of consuming meals away from home assessed using a MANCOVA did not reveal significant $F$ values for BMI classification (Wilks' Lambda $=1.00, F[12,7034]=$ 1.44, $P=0.140, \eta_{p}^{2}=0.002$ ) or the interaction between BMI classification and gender (Wilks' Lambda $=1.00$, $F[12,7034]=1.27, P=0.227, \eta_{p}^{2}=0.002$ ) (Table 3).

3.4. Physical Activity. Significant differences were observed in physical activity levels between non-overweight and obese students, and between overweight and obese students $(F[2,3669]=15.78, P<0.001)$ based on ANOVA. Both non-overweight $(2.92 \pm 0.01[\mathrm{SE}], P<0.001)$ and overweight students $(2.89 \pm 0.03, P<0.001)$ were more active than obese students $(2.66 \pm 0.05)$. Differences were also observed between BMI classifications based on gender for both boys $(F[2,1747]=23.12, P<0.001)$ and girls $(F[2,1919]=3.07, P=0.047)$ when assessed using ANOVA. Both non-overweight $(3.06 \pm 0.02, P<0.001)$ and overweight boys $(3.00 \pm 0.04, P<0.001)$ were more active than obese boys $(2.63 \pm 0.06)$, while non-overweight girls $(2.81 \pm$ $0.02, P=0.048)$ were more active than obese girls $(2.70 \pm$ $0.07)$.

\section{Discussion}

The purpose of this study was to investigate the overweight and obesity status of Alberta adolescents and to identify differences in nutrient intakes, meal behaviours, and physical activity levels between BMI classifications using a web-based survey. One in five students were considered overweight or obese. They had significantly different nutrient intakes, meal behaviours, and physical activity levels than non-overweight students, such that suboptimal behaviours (e.g., skipping breakfast) were more prevalent in students classified as overweight or obese.

Self-reported height and weight were used to calculate BMI and to further classify students as overweight or obese. Although measured height and weight are more precise and accurate than self-reported measurements, self-report is a useful method that offers researchers a time- and costeffective method to survey a large number of participants simultaneously [24, 39-41]. Overweight and obesity rates in the current study were similar to the Alberta rates from the 2004 CCHS [1]. The 2004 CCHS revealed that Alberta youth had a significantly lower prevalence of overweight/obesity than the national average, therefore it was most appropriate to compare to provincial statistics [1].

The association between dietary fat and weight status in the literature is inconclusive. Several researchers have suggested that an increase in dietary fat intake can be correlated to an increase in body fat in children 4 to 11 years [42-44]. However, Gillis and colleagues [45] and Troiano et al. [46] did not observe the same effect. In the current study, both overweight and obese students consumed significantly more total fat compared to non-overweight students, suggesting a relationship between dietary fat intake and BMI classification. In addition, overweight and obese students 
TABLE 2: Group differences in adjusted* nutrient intakes based on BMI classification ${ }^{\dagger}$.

\begin{tabular}{|c|c|c|c|c|c|}
\hline & \multicolumn{3}{|c|}{ BMI Classification $^{\ddagger}($ mean \pm SE $)$} & \multirow{2}{*}{$F$ value } & \multirow{2}{*}{$P$ value } \\
\hline & Non-overweight ${ }^{\S}$ & Overweight & Obese & & \\
\hline \multicolumn{6}{|l|}{ Nutrients $(g)(n=4080)$} \\
\hline Carbohydrate & $284.09 \pm 0.99^{\mathrm{a}}$ & $275.13 \pm 2.25^{\mathrm{b}}$ & $275.35 \pm 3.52^{\mathrm{b}, \mathrm{c}}$ & 8.88 & $<0.001^{\mathrm{ab}} ; 0.016^{\mathrm{ac}}$ \\
\hline Protein & $79.66 \pm 0.46$ & $81.95 \pm 1.04$ & $79.09 \pm 1.63$ & 2.25 & nsd \\
\hline Fat & $77.36 \pm 0.36^{\mathrm{a}}$ & $79.95 \pm 0.82^{\mathrm{b}}$ & $81.14 \pm 1.29^{b, c}$ & 7.51 & $0.004^{\mathrm{ab}, \mathrm{ac}}$ \\
\hline Fibre & $15.14 \pm 0.13^{\mathrm{a}}$ & $13.97 \pm 0.29^{\mathrm{b}}$ & $13.79 \pm 0.46^{\mathrm{b}, \mathrm{c}}$ & 9.86 & $<0.001^{\mathrm{ab}} ; 0.005^{\mathrm{ac}}$ \\
\hline \multicolumn{6}{|c|}{ Other food groups subcategories (servings/day) $(n=4080)$} \\
\hline Mostly sugar & $1.01 \pm 0.03$ & $0.91 \pm 0.06$ & $0.99 \pm 0.10$ & 1.12 & nsd \\
\hline High salt/fat & $0.62 \pm 0.02$ & $0.58 \pm 0.05$ & $0.64 \pm 0.07$ & 0.29 & nsd \\
\hline High calorie beverages & $0.79 \pm 0.02$ & $0.84 \pm 0.05$ & $1.09 \pm 0.09$ & 5.73 & $\mathrm{nsd}^{* *}$ \\
\hline Low calorie beverages & $1.25 \pm 0.04$ & $1.30 \pm 0.08$ & $1.33 \pm 0.12$ & 0.35 & nsd \\
\hline High sugar/fat & $0.67 \pm 0.02$ & $0.61 \pm 0.04$ & $0.54 \pm 0.06$ & 2.96 & nsd \\
\hline
\end{tabular}

BMI: Body Mass Index; g: grams; nsd: no significant difference; SE: standard error of the mean.

* Adjusted for total caloric intake (energy).

${ }^{\dagger}$ Univariate analyses.

${ }^{\ddagger}$ Classified according to the International Obesity Task Force cut-offs [22].

$\S$ Non-overweight refers to all non-overweight, non-obese students.

** Significance was not observed based on multivariate analysis, however, univariate analysis revealed significance between non-overweight and obese students $(P=0.003)$.

${ }^{\mathrm{a}, \mathrm{b}, \mathrm{c}}$ Different superscript letters in each row indicate significant statistical differences.

TABLE 3: Group differences in suboptimal meal behaviours* based on BMI classification ${ }^{\dagger}$.

\begin{tabular}{|c|c|c|c|c|c|}
\hline & \multicolumn{3}{|c|}{ BMI Classification $^{\ddagger}($ mean \pm SE $)$} & \multirow{2}{*}{$F$ value } & \multirow{2}{*}{$P$ value } \\
\hline & Non-overweight ${ }^{\S}$ & Overweight & Obese & & \\
\hline \multicolumn{6}{|c|}{ Meal frequency** $(n=3114)$} \\
\hline Breakfast & $4.25 \pm 0.03^{\mathrm{a}}$ & $4.14 \pm 0.06$ & $4.02 \pm 0.09^{c}$ & 4.35 & $0.014^{\mathrm{ac}}$ \\
\hline Lunch & $4.66 \pm 0.02$ & $4.64 \pm 0.04$ & $4.51 \pm 0.06$ & 2.95 & nsd \\
\hline Dinner & $4.87 \pm 0.01$ & $4.89 \pm 0.02$ & $4.78 \pm 0.04$ & 2.83 & nsd \\
\hline Snacks & $3.55 \pm 0.02^{\mathrm{a}}$ & $3.31 \pm 0.05^{\mathrm{b}}$ & $3.25 \pm 0.08^{\mathrm{b}, \mathrm{c}}$ & 16.67 & $<0.001^{\mathrm{ab}, \mathrm{ac}}$ \\
\hline \multicolumn{6}{|c|}{ Consuming meals and snacks away from home ${ }^{\dagger \dagger}(n=3529)$} \\
\hline School cafeteria & $2.33 \pm 0.03$ & $2.35 \pm 0.06$ & $2.40 \pm 0.10$ & 0.27 & nsd \\
\hline Fast food/take out & $2.31 \pm 0.02$ & $2.26 \pm 0.04$ & $2.19 \pm 0.06$ & 2.40 & nsd \\
\hline Other restaurant & $2.05 \pm 0.02$ & $2.08 \pm 0.04$ & $2.06 \pm 0.06$ & 0.37 & nsd \\
\hline Vending machines & $2.19 \pm 0.02$ & $2.16 \pm 0.05$ & $2.18 \pm 0.08$ & 0.22 & nsd \\
\hline Snack bars & $2.25 \pm 0.02$ & $2.15 \pm 0.05$ & $2.17 \pm 0.08$ & 1.93 & nsd \\
\hline Convenience store & $2.52 \pm 0.02$ & $2.51 \pm 0.05$ & $2.56 \pm 0.08$ & 0.20 & nsd \\
\hline
\end{tabular}

BMI: Body Mass Index; nsd: no significant difference; SE: standard error of the mean.

* Adjusted for total caloric intake (energy).

${ }^{\dagger}$ Univariate analyses.

${ }^{\ddagger}$ Classified according to the International Obesity Task Force cut-offs [22].

$\S$ Non-overweight refers to all non-overweight, non-obese students.

** Meal frequency: never $=1$, on weekends only $=2$, less than half of the week $(\leq 3$ days/week $)=3$, more than half of the week $(\geq 4$ days $/$ week $)=4$, every day $=5$; snacks were averaged before analysis (morning snacks, afternoon snacks, evening snacks).

${ }^{\dagger \dagger}$ Consuming meals and snacks away from home: rarely or never $=1$, once a month $=2$, once a week $=3,2-6$ times a week $=4$, once a day $=5$.

$\mathrm{a}, \mathrm{b}, \mathrm{c} D$ ifferent superscript letters in each row indicate significant statistical differences.

had significantly lower intakes of carbohydrate and fibre compared to their peers. Although mean intakes of total fibre were well below the recommended Dietary Reference Intake (DRI) in all BMI categories, higher intakes were observed in non-overweight students, representing an improvement in fibre intake with decreasing BMI. Significant differences were not observed between BMI classification and diet quality; however, recent findings from the 2004 CCHS suggested that youth who consumed fruits and vegetables more frequently (five or more times a day) were less likely to be classified as overweight/obese [1]. However, it is worth noting that diet quality was very poor in all students, regardless of weight status, which could explain the lack of significance in results [17]. Further, the food-based diet quality index used in the present study did not determine when students exceeded their CFGHE recommendations, which may provide a better 
understanding of the relationship between diet quality and overweight/obesity.

Although results did not indicate significance for the consumption of Other Foods subcategories, univariate analysis revealed that obese students consumed significantly more high calorie beverages compared to non-overweight students. The relationship between high calorie beverages (e.g., regular soft drinks) and body weight is of interest due to the tremendous increase in soft drink consumption in the adolescent population. In the United States, data from the National Heart, Lung, and Blood Institute Growth and Health Survey assessed longitudinal changes in beverage consumption among adolescent girls. Girls were assessed initially at age 9 or 10 years and annually up until 19 years of age. Data from multiple 3-day food records indicated that regular soft drink consumption nearly tripled over the 10 -year period. In that study, for every 100 grams of regular soft drinks consumed, BMI increased by 0.01 unit and average daily caloric intake increased by approximately 82 kilocalories [12]. A more recent Australian study indicated that schoolchildren aged 4 to 12 years who consumed greater intakes of high calorie beverages (i.e., fruit juice/drink, soft drink) were more than twice as likely to be overweight/obese [13]. A metaanalysis which examined the effects of soft drink consumption on nutrition and health revealed positive associations between soft drink consumption and body weight, although results varied depending on the methodology used to assess body weight [47].

Results of the present study indicated that nonoverweight students had a higher frequency of consuming breakfast and snacks when compared to either overweight or obese students. Breakfast skipping is highly prevalent in the adolescent population, and consistent with previous reports, has been associated with increased prevalence of overweight [48]. Although snack consumption has been previously associated with higher intakes of Other Foods [49], the current results suggest that snacks may be associated with a lower BMI classification. Additional research that examines meal patterns may be helpful in clarifying the association between snack consumption and weight. Although significant differences were not observed between BMI classification and consumption of meals and snacks away from home, previous studies have found a positive association [50,51]. This suggests that location alone may not be adequate to explain the relationship between meal behaviours and overweight/obesity. Information regarding the type (e.g., fried versus grilled, white versus whole wheat, whole versus skim milk, juice versus fruit) and quantity of the food consumed away from home may be necessary to provide a true understanding of the relationship between BMI classification and meal location. As well, in the current study, the frequency of family meals was not examined. Family meals may have provided a better understanding of BMI classification than consumption of meals away from home at independent locations.

Results from the current study indicated that both nonoverweight and overweight students were more active than obese students. Further, differences were observed by gender where both non-overweight and overweight boys were more active than obese boys, and non-overweight girls were more active than obese girls. These findings are consistent with results from the 2004 CCHS which indicated that sedentary adolescent boys were more likely than active boys to be obese [1]. However, these results are dissimilar to other reports from the Canadian Health Measures Survey that utilized objective measuring devices for physical activity such as accelerometers [52]. In a study done by Thompson et al. [14], no significant differences were found in physical activity levels among BMI classifications.

A limitation of this study was the use of self-reported survey data. Although validated survey components were used, many adolescents experience recall bias, response bias, and underreporting of total energy intake which is known to occur in the adolescent population [53]. Strengths of this study include the large sample size, the use of validated questionnaires to assess behaviours, and the web-based methodology which facilitated access to a large number of students over a large geographic area. The survey also provided anonymity and privacy which have been shown to be important determinants of adolescents' decision to report honest answers [54]. Further, students were not aware in advance what day the survey was to be completed, therefore reducing reactivity.

\section{Conclusions}

In conclusion, this study examined the overweight and obesity status of Alberta adolescents and the associations between BMI classification and lifestyle behaviours including nutrient intakes, meal behaviours, and levels of physical activity using a web-based survey. Web-SPAN was a timeand cost-effective method that was used to assess health behaviours of adolescents throughout a wide geographic area, including hard-to-reach areas. Significant differences in intake, meal behaviours, and physical activity levels existed between BMI classifications. This research supports the need to target suboptimal behaviours such as high calorie beverage consumption, total fat intake, breakfast skipping, and low levels of physical activity in order to promote healthy weights in the adolescent population. Because behaviours established during adolescence have been shown to track into adulthood, it is important to target these behaviours during early adolescence. In Alberta, vending machines have been removed from many schools, and daily physical activity is mandatory in grades 1-9; however, this research supports the need to focus on older adolescents, including those in high school (grades 10 through 12). Additional nutrition education in schools may also help target suboptimal nutritional intakes such as high intakes of total fat and low intakes of fibre, by educating students on the importance of a healthy diet. Thus, priorities that aim to improve the whole school environment such as comprehensive school health which includes school nutrition policies, removal of vending machines, and mandatory physical activity may help to improve overall weight status in Alberta adolescents. Further, because diet quality was poor among all Alberta adolescents, regardless of weight status, priorities should be developed 
that target students in all grade levels in order to improve the overall health and well-being of all adolescents.

\section{Conflict of Interests}

The authors declare that they have no conflict of interests.

\section{Acknowledgments}

This research was supported by Alberta Innovates-Health Solutions (AIHS; formerly the Alberta Heritage Foundation for Medical Research [AHFMR]) and the Canadian Institutes of Health Research/Heart and Stroke Foundation (CIHR/HSF). K. E. Storey received funding from the Danone Institute of Canada (Doctoral Student Award), CIHR/HSF, and AIHS Health Research Studentship. R. C. Plotnikoff and K. D. Raine were funded by Salary Awards from the CIHR and AIHS; K. D. Raine was also funded from an HSF Salary Award.

\section{References}

[1] M. Shields, "Nutrition: findings from the Canadian Community Health Survey: measured Obesity: overweight Canadian children and adolescents," Miscellaneous Papers, no. 82, pp. 134, 2005.

[2] C. A. Brosnan, S. Upchurch, and B. Schreiner, "Type 2 diabetes in children and adolescents: an emerging disease," Journal of Pediatric Health Care, vol. 15, no. 4, pp. 187-193, 2001.

[3] S. S. Guo, W. Wu, W. C. Chumlea, and A. F. Roche, "Predicting overweight and obesity in adulthood from body mass index values in childhood and adolescence," American Journal of Clinical Nutrition, vol. 76, no. 3, pp. 653-658, 2002.

[4] D. S. Freedman, L. K. Khan, M. K. Serdula, W. H. Dietz, S. R. Srinivasan, and G. S. Berenson, "The relation of childhood BMI to adult adiposity: the Bogalusa heart study," Pediatrics, vol. 115, no. 1, pp. 22-27, 2005.

[5] A. Must and R. S. Strauss, "Risks and consequences of childhood and adolescent obesity," International Journal of Obesity, vol. 23, supplement 2, pp. S2-S11, 1999.

[6] P. T. Katzmarzyk and I. Janssen, "The economic costs associated with physical inactivity and obesity in Canada: an update," Canadian Journal of Applied Physiology, vol. 29, no. 1, pp. 90-115, 2004.

[7] Canadian Medical Association, "2006 Canadian clinical practice guidelines on the management and prevention of obesity in adults and children [summary]," Canadian Medical Association Journal, vol. 176, no. 8, pp. S1-13, 2007.

[8] J. Eaton and C. W. Struthers, "Using the Internet for organizational research: a study of cynicism in the workplace," Cyberpsychology and Behavior, vol. 5, no. 4, pp. 305-313, 2002.

[9] K. E. Storey and L. J. McCargar, "Reliability and validity of Web-SPAN, a web-based method for assessing weight status, diet and physical activity in youth," Journal of Human Nutrition and Dietetics. In press.

[10] P. Ravussin and P. A. Tataranni, "Dietary fat and human obesity," Journal of the American Dietetic Association, vol. 97, no. 7, pp. S42-S46, 1997.
[11] D. S. Ludwig, K. E. Peterson, and S. L. Gortmaker, "Relation between consumption of sugar-sweetened drinks and childhood obesity: a prospective, observational analysis," Lancet, vol. 357, no. 9255, pp. 505-508, 2001.

[12] R. H. Striegel-Moore, D. Thompson, S. G. Affenito et al., "Correlates of beverage intake in adolescent girls: the National Heart, Lung, and Blood Institute Growth and Health Study," Journal of Pediatrics, vol. 148, no. 2, pp. 183-187, 2006.

[13] A. M. Sanigorski, A. C. Bell, and B. A. Swinburn, "Association of key foods and beverages with obesity in Australian schoolchildren," Public Health Nutrition, vol. 10, no. 2, pp. 152-157, 2007.

[14] A. M. Thompson, P. D. Campagna, L. A. Rehman, R. J. Murphy, R. L. Rasmussen, and G. W. Ness, "Physical activity and body mass index in grade 3, 7, and 11 Nova Scotia students," Medicine and Science in Sports and Exercise, vol. 37, no. 11, pp. 1902-1908, 2005.

[15] M. S. Tremblay and J. D. Willms, "Is the Canadian childhood obesity epidemic related to physical inactivity?" International Journal of Obesity, vol. 27, no. 9, pp. 1100-1105, 2003.

[16] M. S. Tremblay, M. Shields, M. Laviolette, C. L. Craig, I. Janssen, and S. C. Gorber, "Fitness of Canadian children and youth: results from the 2007-2009 Canadian Health Measures Survey," Health Reports, vol. 21, no. 1, pp. 7-20, 2010.

[17] K. E. Storey, L. E. Forbes, S. N. Fraser et al., "Diet quality, nutrition and physical activity among adolescents: the Web-SPAN (Web-Survey of Physical Activity and Nutrition) project," Public Health Nutrition, vol. 12, no. 11, pp. 20092017, 2009.

[18] R. C. Plotnikoff, N. Karunamuni, J. C. Spence et al., "Chronic disease-related lifestyle risk factors in a sample of Canadian adolescents," Journal of Adolescent Health, vol. 44, no. 6, pp. 606-609, 2009.

[19] L. E. Forbes, K. E. Storey, S. N. Fraser et al., "Dietary patterns associated with glycemic index and glycemic load among Alberta adolescents," Applied Physiology, Nutrition and Metabolism, vol. 34, no. 4, pp. 648-658, 2009.

[20] J. C. Spence, C. M. Blanchard, M. Clark, R. C. Plotnikoff, K. E. Storey, and L. McCargar, "The role of self-efficacy in explaining gender differences in physical activity among adolescents: a multilevel analysis," Journal of Physical Activity and Health, vol. 7, no. 2, pp. 176-183, 2010.

[21] L. M. Minaker, K. E. Storey, K. D. Raine et al., "Associations between the perceived presence of vending machines and food and beverage logos in schools and adolescents-diet and weight status," Public Health Nutrition, vol. 14, no. 8, pp. 1350-1356, 2011.

[22] T. J. Cole, M. C. Bellizzi, K. M. Flegal, and W. H. Dietz, "Establishing a standard definition for child overweight and obesity worldwide: international survey," British Medical Journal, vol. 320, no. 7244, pp. 1240-1243, 2000.

[23] Dietitians of Canada, Canadian Paediatric Society, The College of Family Physicians of Canada, and Community Health Nurses Association of Canada, "The use of growth charts for assessing and monitoring growth in Canadian infants and children," Canadian Journal of Dietetic Practice and Research, vol. 65 , no. 1, pp. 22-32, 2004.

[24] R. M. Hanning, L. Jessup, I. Lambraki, C. MacDonald, and L. McCargar, "A web-based approach to assessment of food intake and behaviour of school children and adolescents," Canadian Foundation for Dietetic Research Symposium, pp. S110-S111, 2003.

[25] L. M. Minaker, L. McCargar, I. Lambraki et al., "School region socio-economic status and geographic locale is associated with 
food behaviour of Ontario and Alberta adolescents," Canadian Journal of Public Health, vol. 97, no. 5, pp. 357-361, 2006.

[26] M. R. Löwik, K. F. Hulshof, and J. H. Brussaard, "Food-based dietary guidelines: some assumptions tested for the Netherlands," British Journal of Nutrition, vol. 81, supplement 2, pp. S143-S149, 1999.

[27] Health Canada, "Canada's Food Guide to Healthy Eating," http://www.hc-sc.gc.ca/fn-an/alt_formats/hpfb-dgpsa/pdf/ food-guide-aliment/fg_rainbow-arc_en_ciel_ga_e.pdf, 1992.

[28] Health Canada, "Canadian Nutrient File," http://www.hc-sc .gc.ca/fn-an/nutrition/fiche-nutri-data/cnf_aboutus-aproposdenous_fcen-eng.php, 2001.

[29] Health Canada, "Eating Well with Canada's Food Guide," http://www.hc-sc.gc.ca/fn-an/alt_formats/hpfb-dgpsa/pdf/ food-guide-aliment/view_eatwell_vue_bienmang_e.pdf, 2007.

[30] Alberta Learning, "Health and life skills, kindergarten to grade 9," http://www.education.gov.ab.ca/k_12/curriculum/bySubject/healthpls/health.pdf, 2002.

[31] Alberta Learning, "Career and technology studies," http:// www.education.gov.ab.ca/k\%5F12/curriculum/bySubject/cts/ foods/fodpos.pdf, 2005.

[32] D. Neumark-Sztainer, M. M. Wall, M. Story, and C. L. Perry, "Correlates of unhealthy weight-control behaviors among adolescents: implications for prevention programs," Health Psychology, vol. 22, no. 1, pp. 88-98, 2003.

[33] D. Neumark-Sztainer, M. Story, P. J. Hannan, C. L. Perry, and L. M. Irving, "Weight-related concerns and behaviors among overweight and nonoverweight adolescents: implications for preventing weight-related disorders," Archives of Pediatrics and Adolescent Medicine, vol. 156, no. 2, pp. 171-178, 2002.

[34] K. C. Kowalski, P. R. E. Crocker, and R. M. Donen, "The Physical Activity Questionnaire for Older Children (PAQC) and Adolescents (PAQ-A) manual," http://hkin.educ.ubc .ca/behavioural/PAQ\%20manual.pdf, 2004.

[35] P. R. E. Crocker, D. A. Bailey, R. A. Faulkner, K. C. Kowalski, and R. Mcgrath, "Measuring general levels of physical activity: preliminary evidence for the physical activity questionnaire for older children," Medicine and Science in Sports and Exercise, vol. 29, no. 10, pp. 1344-1349, 1997.

[36] K. C. Kowalski, P. R. E. Crocker, and R. A. Faulkner, "Validation of the physical activity questionnaire for older children," Pediatric Exercise Science, vol. 9, no. 2, pp. 174-186, 1997.

[37] K. T. D'Alonzo, “The Johnson-Neyman procedure as an alternative to ANCOVA," Western Journal of Nursing Research, vol. 26, no. 7, pp. 804-812, 2004.

[38] B. G. Tabachnick and L. S. Fidell, Using Multivariate Statistics, Pearson Education, New York, NY, USA, 5th edition, 2007.

[39] R. S. Strauss, "Comparison of measured and self-reported weight and height in a cross-sectional sample of young adolescents," International Journal of Obesity, vol. 23, no. 8, pp. 904-908, 1999.

[40] J. H. Himes and A. Faricy, "Validity and reliability of selfreported stature and weight of US adolescents," American Journal of Human Biology, vol. 13, no. 2, pp. 255-260, 2001.

[41] N. D. Brener, T. McManus, D. A. Galuska, R. Lowry, and H. Wechsler, "Reliability and validity of self-reported height and weight among high school students," Journal of Adolescent Health, vol. 32, no. 4, pp. 281-287, 2003.

[42] L. A. Tucker, G. T. Seljaas, and R. L. Hager, "Body fat percentage of children varies according to their diet composition," Journal of the American Dietetic Association, vol. 97, no. 9, pp. 981-986, 1997.
[43] C. Maffeis, L. Pinelli, and Y. Schutz, "Fat intake and adiposity in 8 to 11-year-old obese children," International Journal of Obesity, vol. 20, no. 2, pp. 170-174, 1996.

[44] E. Obarzanek, G. B. Schreiber, P. B. Crawford et al., "Energy intake and physical activity in relation to indexes of body fat: the National Heart, Lung, and Blood Institute Growth and Health Study," American Journal of Clinical Nutrition, vol. 60, no. 1, pp. 15-22, 1994.

[45] L. J. Gillis, L. C. Kennedy, A. M. Gillis, and O. Bar-Or, "Relationship between juvenile obesity, dietary energy and fat intake and physical activity," International Journal of Obesity, vol. 26, no. 4, pp. 458-463, 2002.

[46] R. P. Troiano, R. R. Briefel, M. D. Carroll, and K. Bialostosky, "Energy and fat intakes of children arid adolescents in the United States: data from the National Health and Nutrition Examination Surveys," American Journal of Clinical Nutrition, vol. 72, no. 5, pp. 1343S-1353S, 2000.

[47] L. R. Vartanian, M. B. Schwartz, and K. D. Brownell, "Effects of soft drink consumption on nutrition and health: a systematic review and meta-analysis," American Journal of Public Health, vol. 97, no. 4, pp. 667-675, 2007.

[48] G. C. Rampersaud, M. A. Pereira, B. L. Girard, J. Adams, and J. D. Metzl, "Breakfast habits, nutritional status, body weight, and academic performance in children and adolescents," Journal of the American Dietetic Association, vol. 105, no. 5, pp. 743-760, 2005.

[49] D. Garriguet, "Nutrition: Findings from the Canadian Community Health Survey: Overview of Canadians' eating habits," http://www.statcan.ca/english/research/82-620-MIE/82-620MIE2006002.pdf, 2004.

[50] P. J. Veugelers and A. L. Fitzgerald, "Prevalence of and risk factors for childhood overweight and obesity," Canadian Medical Association Journal, vol. 173, no. 6, pp. 607-613, 2005.

[51] H. M. Niemeier, H. A. Raynor, E. E. Lloyd-Richardson, M. L. Rogers, and R. R. Wing, "Fast food consumption and breakfast skipping: predictors of weight gain from adolescence to adulthood in a nationally representative sample," Journal of Adolescent Health, vol. 39, no. 6, pp. 842-849, 2006.

[52] R. C. Colley, D. Garriguet, I. Janssen, C. L. Craig, J. Clarke, and M. S. Tremblay, "Physical activity of Canadian children and youth: accelerometer results from the 2007 to 2009 Canadian Health Measures Survey," Health Reports, vol. 22, no. 1, pp. 19, 2011.

[53] L. G. Bandini, A. Must, H. Cyr, S. E. Anderson, J. L. Spadano, and W. H. Dietz, "Longitudinal changes in the accuracy of reported energy intake in girls 10-15 y of age," American Journal of Clinical Nutrition, vol. 78, no. 3, pp. 480-484, 2003.

[54] A. J. Supple, W. S. Aquilino, and D. L. Wright, "Collecting sensitive self-report data with laptop computers: impact on the response tendencies of adolescents in a home interview," Journal of Research on Adolescence, vol. 9, no. 4, pp. 467-488, 1999. 


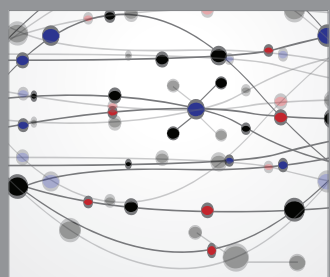

The Scientific World Journal
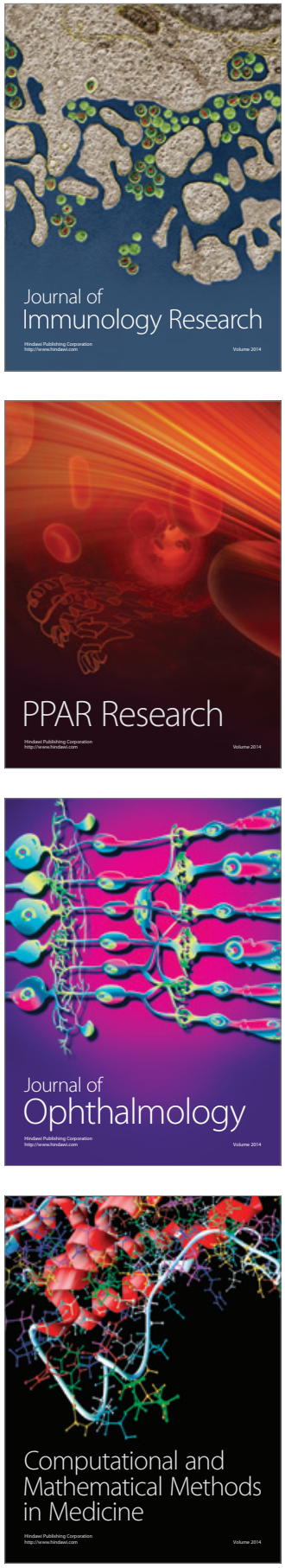

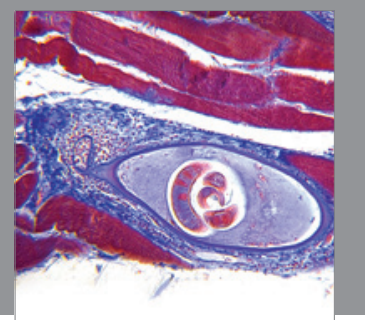

Gastroenterology

Research and Practice
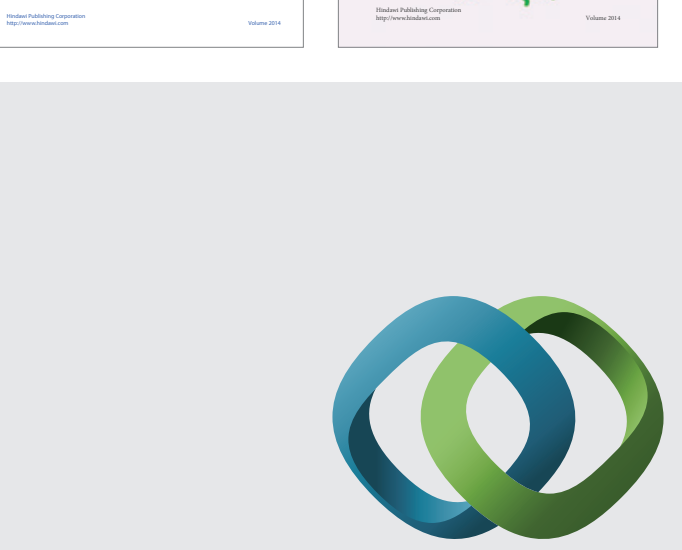

\section{Hindawi}

Submit your manuscripts at

http://www.hindawi.com
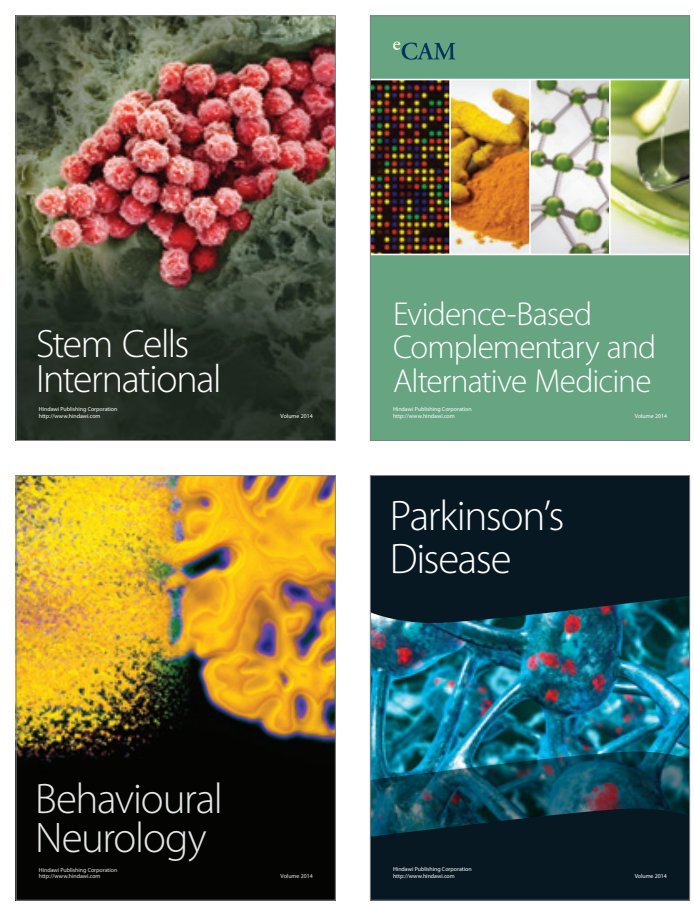

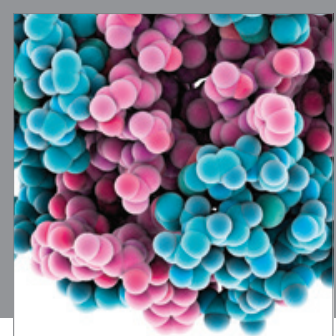

Journal of
Diabetes Research

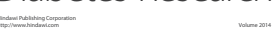

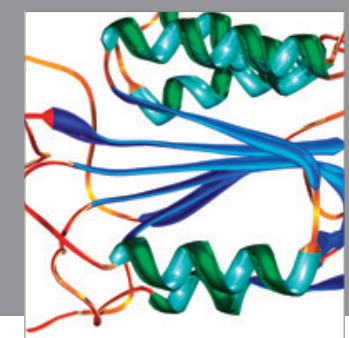

Disease Markers
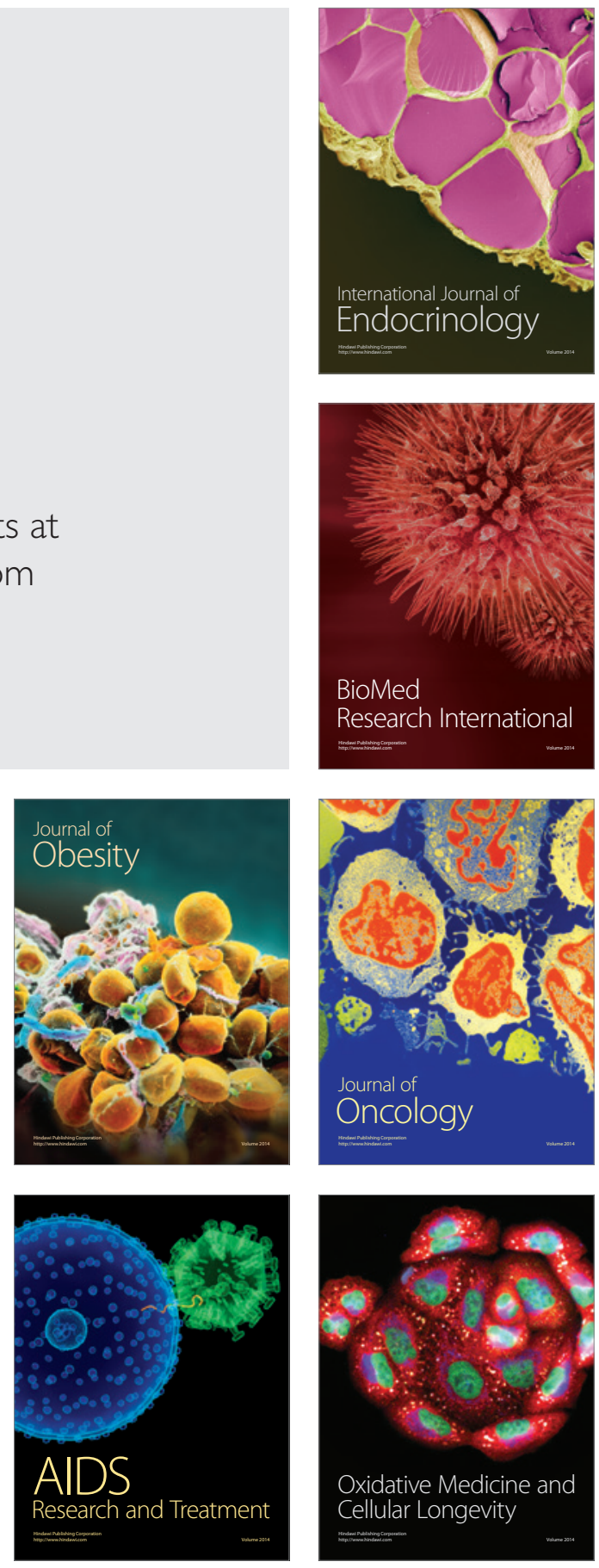